\title{
Work as Motivator
}

\section{Murali Chemuturi*}

Chemuturi Consultant, USA

There are many theories of motivation and we know about most of them. But there is little literature on using work as the motivator. But work is the most potent of all motivators and when we realize this, we would be able to motivate the people to unimaginable levels of performance.

You might have seen people at checkout counters in malls on the black Friday (the day after the Thanksgiving in the USA) or such other places where long queues are formed. Usually the people behind counters in these situations are paid the minimum or slightly above the minimum wage but they work with a frenzy to complete each transaction very quickly and accurately. What motivates them to such peak performance? It is the thought that other human beings are waiting for their attention propels them. Second, no one wants to have pending work. The waiting line indicates pending work and the individual hurries up to clear the backlog.

People come to work basically to earn a living. When they go home at the end of each work-day, they would like to go with their head held high with the pride of having contributed to the organization they work for. If they have to go back in the evening doing nothing, they are bereft of that pride that comes with doing something well. They like to see themselves as contributing members of the organization. I have seen cases when people became mentally ill as they were stripped of their responsibility but were retained on the rolls of the organization! They were getting the salary and did not have to do anything at all. It was a sort of on-the-jobretirement. But they lost the pride that comes with achievement of being important and that made them lose their mental balance.

Work gives them pride and ego and to sustain that pride and ego, people would be willing to exert and extend themselves. How can managers utilize this opportunity and motivate their subordinates to higher levels of performance? The following principles would help -

1. Allocate work that is appropriate for the person in terms of the skill/specialty such that it can be executed competently by the individual. This would give them the confidence that they can do.

2. Allocate the work in such a manner that it challenges the individual to stretch his/her skill a bit more than(s) he already possesses. It provides them an opportunity to learn something new.

3. Allocate in advance of the person becoming free so that the individual would be secure that another assignment is pending for his/her attention. This provides the individual with the much-needed security.

4. Set the target such that it makes the individual to increase the pace of execution slightly more than(s) he usually works at. This prevents the individuals from becoming lax and losing the skill.

5. When the individual turns in a better than usual performance, do not hesitate to show appreciation. Remember that every appreciation need not result in a financial reward. Appreciation in itself is a reward most human beings crave for. Individuals look for appreciation from the bosses in addition to money. They can boast to their families about how well they are perceived at the workplace.
6. When the individual turns in a performance that is slightly short of expectations, do not be quick to admonish. Resort to admonishment only in very extenuating circumstances. Admonition by a boss has a severe impact on the pride of the individual the reaction to which can range from depression to rebellion. When admonition becomes necessary, focus on the result but not on the shortcomings of the individual. It is for the individual to analyze himself/herself and realize the shortcomings if any. Right admonition, as the experience shows, is a great tool for improvement of performance if administered in the right manner.

7. Monitor the execution at right intervals. The monitoring should not be breathing down the neck nor should it be total neglect. Both are bad. Monitor such that the individual feels the attention but at the same time take care to see that the individual does not feel spied upon. Right kind of monitoring the work gives the feeling that the assignment is of importance and motivates the individual to higher level of performance.

8. Sometimes, managers fall into the trap of believing that some assignments are very important and some are not. This would demotivate individuals like none other, can. If a person feels that what (s)he does is unimportant, his/her ego would hurt badly and the pride would be lost.

Then the performance ought to be measured at preset periodic intervals for all people in the department. This not only helps benchmarking the performance of the individuals but also gives the individual the level of his/her own performance vis-à-vis the colleagues. This allows and spurs he individuals to se $t$ their own goals for performance improvement over the next measurement cycle.

The measurement of performance ought to result in rewards. Of course, every performance measurement need not result in rewards but rewards ought to be given after a few cycles of performance measurement. Sometimes, it so happens that a single individual turns in outstanding performance in every measurement cycle and lends himself/herself eligible for the reward. Nothing can demotivate more than the feeling to the individual that (s)he stands no chance of getting the reward. When such a scenario presents itself, it is better to elevate the super performer to a higher level and make it possible for others to become the next super performer and a chance to win the coveted reward.

*Corresponding author: Murali Chemuturi, Chemuturi Consultant, USA, E-mail murali@chemuturi.com

Received July 06, 2018; Accepted July 11, 2018; Published July 18, 2018

Citation: Chemuturi M (2018) Work as Motivator. J Account Mark 7: e125. doi: 10.4172/2168-9601.1000e125

Copyright: $\odot 2018$ Chemuturi M. This is an open-access article distributed under the terms of the Creative Commons Attribution License, which permits unrestricted use, distribution, and reproduction in any medium, provided the original author and source are credited. 
What is often neglected is the giving negative rewards. Just as super performance gets reward, poor performance ought to get negative reward. If we neglect this aspect, it sends a message to the rest of the staff that they too can get away with penalty avoidance performance. So, we ought to give negative rewards as periodically as we give positive rewards.

The rewards must be based on thoroughly objective data obtained through meticulous and accurate measurement which is normalized for known abnormalities that prevented better performance.
All these are based on the performance of people on their work they perform. Some feel that motivation is only for blue collar workers. Not so! Even professional workers and managers feel the need for being motivated. What better method is there than to motivate people than work itself?

Just by managing the work carefully, a manager can maintain a high level of morale in his/her team. 